\title{
Investigação de Sequências Didáticas para o Ensino de Agroecologia
}

\author{
Investigation of Didactic Sequences for the Teaching of \\ Agroecology
}

\author{
iD Marcelo Neves Alves ${ }^{1}$ \\ Joana Fidelis da Paixão ${ }^{1}$ \\ 'Instituto Federal de Educação' Ciência e Tecnologia Baiano (IFBA), Catu, BA, Brasil. \\ Autora correspondente: joana.paixao@catu.ifbaiano.edu.br
}

Resumo: Nesta pesquisa foram elaboradas, testadas e avaliadas em sala de aula, duas sequências didáticas destinadas ao ensino de Agroecologia. Preparadas com base na abordagem de Design Research, os planos de aula incluíram uso de textos com informações de base científica, contextualização dos conteúdos em relação ao cotidiano dos estudantes, processo coletivo e cooperativo de aprendizagem, entre outros. A intervenção mostrou efeitos positivos em relação aos princípios de design quanto à motivação dos estudantes e à aprendizagem de conteúdos, sobretudo quanto aos processos e linhas de produção agroecológica. Porém, alguns estudantes, ainda que tivessem que realizar pesquisas para legitimar suas opiniões, permaneceram resistentes às mudanças de entendimento, especialmente em relação às verdadeiras contribuições da Revolução Verde. Isso indica que os princípios de design utilizados devem dar mais foco para a reflexão e interpretação coletiva dos dados em sala de aula.

Palavras-chave: Pesquisa da educação; Ensino médio; Agroecologia; Sequência de ensino.

\begin{abstract}
In this study, two didactic sequences on Agroecology were elaborated, tested and evaluated in the classroom. Those sequences were based on Design Research approach, and the related lesson plans covered science-based texts, the contextualization of the content with the students' lives, cooperative and peer learning processes and so on. The classes resulted in positive outcomes related to the design principles regarding student motivation and content learning, especially on processes and agroecological production models. However, even though some students had to conduct research to legitimize their opinions, they remained resistant to changes of understanding, especially in relation to the true contributions of the Green Revolution. This suggests that the design principles used should focus more on the reflection and collective interpretation of data in class.
\end{abstract}

Keywords: Design research; High school; Agroecology; Teaching sequence.

Recebido em: 23/01/2019

Aprovado em: 20/10/2019 


\section{Introdução}

Com os avanços tecnológicos e a reorganização produtiva do campo brasileiro, baseados nos preceitos da Revolução Verde e no paradigma da modernização da produção agrícola, desde os anos de 1960, os cursos de ciências agrárias formam profissionais para atender ao padrão tecnológico da agricultura convencional, seguindo a racionalidade econômica e os modelos técnicos produtivistas (AGUIAR, 2010).

Com a publicação da Política Nacional de Agroecologia e Produção Orgânica, através do Decreto No 7.794/202 (BRASIL, 2012) que objetivou integrar, articular e adequar as diversas políticas, programas e ações que visam induzir a transição agroecológica e fomentar a produção orgânica e de base agroecológica, foi determinado que a formação profissional estivesse entre os instrumentos dessa política.

Em 2013, foi divulgado o Plano Nacional de Agroecologia e Produção Orgânica (PLANAPO) (CONGRESO IBERO AMERICANO DE PSICOLOGÍA DE LAS ORGANIZACIONES Y EL TRABAJO, 2013), o qual destacou que a escassez de profissionais com conhecimento em Agroecologia e na Produção Orgânica dificulta que os/as agricultores/as recebam assistência técnica nessa área. Segundo o PLANAPO, a inclusão e o incentivo à abordagem da agroecologia e dos sistemas orgânicos de produção ensino representa alguns dos principais desafios a serem superados nos diferentes níveis e modalidades de educação. O documento aponta que algumas iniciativas começaram a minimizar esse quadro, com destaque para a oferta de Cursos de Agroecologia em quase todos os estados brasileiros pelos Institutos Federais de Educação, Ciência e Tecnologia (IFE).

Contudo, no âmbito dos Cursos Técnicos ofertados pelos IFEs, há uma carência de material didático específico para o público alvo de cursos técnicos em Agroecologia e o contexto educacional voltado para o ensino de Agroecologia, visto que os livros disponíveis nas bibliotecas que abordam esse tema, apesar de apresentarem informações essenciais, possuem linguagem muito técnica, leitura complexa e pouco atraente para os estudantes.

O Instituto Federal de Educação, Ciência e Tecnologia Baiano, câmpus Catu, oferta, dentre outros cursos, o Curso Técnico em Agropecuária Integrado ao Ensino Médio e capacita profissionais para que estes atuem na transformação"[...] dos meios de produção agropecuária, através de um desenvolvimento sustentável" e na "utilização racional dos recursos disponíveis, com a finalidade de evitar o desgaste do solo, dos recursos hídricos, da flora e da fauna natural, mantendo o equilíbrio ambiental", de acordo com o que preconiza a Lei no 9.394, de 20 de dezembro de 1996, a Lei de Diretrizes e Bases (LDB) da Educação (BRASIL, 1996). Com isso, a instituição busca promover a formação de profissionais que contribuem para uma perspectiva que visa não apenas o fortalecimento da economia, mas que também entenda suas relações com o meio ambiente.

Beatrici e Mello (2007) acreditam que um dos grandes desafios do ensinoaprendizagem em Agroecologia é apontar a necessidade de novos paradigmas científicos para a construção do conhecimento. O modelo de ensino predominante ainda é pautado na transmissão de conhecimentos e carece de esforços de contextualização dos conhecimentos abordados em sala de aula com relação à vida cotidiana dos alunos.

Durante a formação de técnicos em Agropecuária, comprometidos com um projeto sustentável e democrático de desenvolvimento rural e agroecológico, são inúmeras as dificuldades enfrentadas nos processos de aprendizagem e situações ligadas ao contexto escolar (AGUIAR, 2010). A Agroecologia envolve conhecimentos de natureza multidisciplinar 
para a oferta de alimentos saudáveis à população e é uma proposta de agricultura baseada na justiça social, viabilidade econômica e sustentabilidade ecológica, que tem emergido com base em novas tecnologias de manejo da área produtiva (solo, água, biodiversidade, etc.) e de manejo de pragas e doenças, sem que se faça uso de agrotóxicos (ARAÚJO et al., 2012). Os desafios do ensino dessa temática estão em proporcionar meios para que ocorra uma discussão ampliada sobre os princípios da Agroecologia, através de uma reflexão crítica e abrangente a respeito dos valores culturais e pressões econômicas envolvendo o assunto.

Assim, surge a necessidade de adotar estratégias para o ensino da Agroecologia, promovendo condições para que os estudantes construam uma visão da importância da produção agrícola sustentável. Nesse contexto, a pesquisa aqui proposta visa superar, ainda que parcialmente, o problema da escassez de material didático sobre Agroecologia, adequado ao público-alvo de cursos técnicos dos Institutos Federais de Educação, Ciência e Tecnologia. Dessa forma, a pesquisa foi desenvolvida com base na abordagem de Design Research (PLOMP; NIEVEEN, 2009) para a elaboração de sequência didática (SD), com vistas a promover uma discussão sobre o modelo convencional de produção de alimentos e a compreensão de princípios agroecológicos, no contexto do ensino médio integrado.

Esta pesquisa teve o objetivo de desenvolver, aplicar e analisar sequências didáticas sobre Agroecologia, elaboradas a partir da abordagem de Design Research, na disciplina 'Agroecologia e Gestão Ambiental', ministrada para turmas do curso Técnico em Agropecuária do Instituto Federal Baiano, câmpus Catu. As sequências didáticas foram utilizadas para melhorar a prática educativa em um contexto educacional específico, com vistas a reduzir o problema da escassez de material didático adequado ao público-alvo da disciplina.

\section{Metodologia}

\section{Abordagem metodológica de design educacional (design research) na elaboração das sequências didáticas sobre agroecologia}

Entende-se por 'sequência didática' um conjunto de atividades ordenadas, estruturadas e articuladas para a realização de certos objetivos educacionais, que têm um princípio e um fim conhecidos tanto pelos professores como pelos alunos (ZABALA, 1998). Uma abordagem metodológica que pode servir de base à produção de sequências didáticas, é o Design Research, que visa desenvolver inovações educacionais e ampliar o conhecimento sobre os processos de planejamento e implementação destas intervenções (PLOMP; NIEVEEN, 2009).

Esta pesquisa foi fundamentada nos referenciais teórico-metodológicos de design educacional (design research), através do estudo sistemático do planejamento, desenvolvimento, avaliação e manutenção de intervenções educacionais, na forma de soluções para problemas complexos da prática educacional. (PLOMP; NIEVEEN, 2009).

No presente estudo, a intervenção educacional consistiu na elaboração e aplicação de sequências didáticas sobre Agroecologia, em turmas de Curso Técnico em Agropecuária. As vias de aprendizagem da intervenção foram efetivamente testadas em sala de aula, possibilitando a validação interna dos princípios de design. 
Os assuntos selecionados para serem abordados nas sequências didáticas foram escolhidos a partir da análise dos conteúdos básicos presentes na ementa da disciplina 'Agroecologia e Gestão Ambiental', no âmbito do curso Técnico em Agropecuária, do IF Baiano, câmpus Catu. As temáticas foram selecionadas e abordadas objetivando a compreensão das questões socioeconômicas e a apresentação da agroecologia como uma ciência emergente que estuda os agrossistemas, integrando conhecimentos de agronomia, ecologia, economia e sociologia.

Para construir as sequências didáticas (SD) foram utilizados os critérios de justificação a priori (MÉHEUT, 2005), divididos em três dimensões: (1) epistemológica: relacionada aos conteúdos a serem aprendidos, à sua aplicabilidade e gênese histórica; (2) psicocognitiva: relativa à possibilida de dos estudantes compreenderem o assunto, dadas as suas capacidades cognitivas; e, (3) didática: que analisa as restrições da escola (cronogramas, carga horária etc.). Para a avaliação das SD, foram aplicados critérios de validação a posteriori (MÉHEUT, 2005), realizando validação interna por meio de fontes de dados, tais como questionários abertos respondidos em grupos, redação argumentativa, debates e aula prática.

Para o planejamento da primeira SD foram considerados princípios históricos, econômicos, sociais e ambientais envolvendo a agricultura convencional; conflitos de interesses (entre empresas, governos, produtores rurais) e a neutralidade das informações veiculadas sobre os produtos relacionados a esse modelo de produção de alimentos.

\section{Sequência didática 1}

A primeira sequência didática intitulada Revolução verde: o advento do pacote tecnológico, agrotóxicos e sementes transgênicas compôs quatro aulas de 50 minutos cada, sendo duas aulas aplicadas por dia, em três turmas diferentes: duas turmas de $3^{\circ}$ ano do Curso Técnico de Agropecuária Integrado ao Ensino Médio, e uma turma do Curso Técnico de Agropecuária, modalidade subsequente, do Instituto Federal de Educação, Ciência e Tecnologia Baiano, câmpus Catu. O primeiro plano de aula, intitulado 'Promessa feita, promessa cumprida? Como a agricultura convencional tem solucionado a fome?' abrangeu as Aulas 1 e 2, e o segundo, 'A neutralidade científica desmitificada na prática: o caso da Chapada do Apodi-CE', compreendeu as Aulas 3 e 4.

As Aulas 1 e 2 tiveram o objetivo de discutir o que são e como surgiram os agrotóxicos, e também provocar reflexões e debates acerca da real contribuição da Revolução Verde na erradicação da fome, no Brasil e no mundo. Assim, as Aulas 1 e 2 da primeira sequência didática foram dedicadas a uma análise crítica do modelo convencional de produção, e incluíram:

- A compreensão do advento histórico do modelo de agricultura convencional (a introdução do pacote tecnológico envolvendo o uso de agrotóxicos e fertilizantes químicos) no Brasil e da expansão do agronegócio, além das suas externalidades negativas (custos ambientais e sociais relacionados);

- Uma análise crítica da atuação do mercado de agrotóxicos, fertilizantes e sementes transgênicas na erradicação da fome;

- A discussão da importância da agricultura familiar para a alimentação e para a economia brasileira, um debate sobre a existência de outros modelos de produção de alimentos, e abordagem da agroecologia como um caminho para o fortalecimento da agricultura familiar. 
Ao final das Aulas 1 e 2, para a realização da primeira coleta de dados da pesquisa, os alunos elaboram um texto dissertativo-argumentativo sobre qual é o papel do agronegócio na erradicação da fome.

As Aulas 3 e 4 foram dedicadas à análise crítica da neutralidade científica em relação ao pacote tecnológico do Agronegócio, através da apreciação de evidências de que as sementes transgênicas aumentaram a dependência do uso de agrotóxicos, ao contrário do prometido pelo setor produtivo. Dessa forma, as Aulas 3 e 4 da primeira sequência didática consistiram de:

- Um debate sobre a desmitificação da neutralidade da ciência;

- Uma abordagem dos tipos de sementes transgênicas mais utilizadas no país e sua dependência do uso de agrotóxicos, ao contrário do prometido;

- Um estudo de caso intitulado Como o agronegócio utiliza o mito do cientificismo: o caso da Chapada do Apodi, CE.

Ao final dessas aulas, foi realizada a segunda coleta de dados, através da condução de atividades reflexivas em grupo. Em equipe, os alunos foram estimulados a realizar uma análise crítica e sistemática dos principais conflitos de interesses envolvendo o uso de agrotóxicos, fertilizantes químicos e sementes transgênicas, tendo como referência o estudo de caso da Chapada do Apodi, CE.

Os alunos refletiram sobre alguns mitos relacionados à ciência, que incluem, por exemplo, o mito de que os resultados de pesquisas científicas são incontestáveis. E depois das reflexões e debates em equipes, em resposta a várias questões relacionadas à neutralidade científica ( $1^{\circ}$ etapa da atividade), os estudantes realizaram uma análise coletiva do processo vivido pelas populações da Chapada do Apodi, CE, relatado por Rigotto et al. (2012). Na segunda etapa da atividade, os alunos relacionaram a propagação de mitos atrelados a esse estudo de caso, descritos pelos autores (RIGOTTO et al., 2012) como tentativas de mascarar o processo de contaminação ambiental e expropriação de terras, vivido pelas populações locais, aos mitos discutidos na primeira etapa.

\section{Sequência didática 2}

Na segunda SD foram planejadas situações de aprendizagem sobre:

- Conceitos, princípios e bases agroecológicas;

- As principais etapas para o desenvolvimento e a implantação do Manejo Integrado de Pragas (MIP);

- Modelos de produção agroecológica, por exemplo, dos Sistemas Agroflorestais (SAFs), que incluem a agricultura Sintrópica.

A segunda sequência didática, intitulada Princípios e bases agroecológicas: um caminho para sustentabilidade, foi desenvolvida em quatro aulas de 50 minutos cada, sendo o plano de aula correspondente às Aulas 3 e 4, denominado 'Manejo Integrado de Pragas (MIP): uso de práticas sustentáveis' e o plano das Aulas 5 e 6, designado como 'Processos e modelos agroecológicos de produção'.

As aulas 5 e 6 tiveram o objetivo de realizar um levantamento dos conhecimentos prévios dos estudantes acerca das principais etapas para o desenvolvimento e a implantação do MIP e promover a aquisição de novos conhecimentos sobre a temática. Assim, as Aulas 5 e 6 da segunda sequência didática foram dedicadas: 
- À discussão da necessidade de ações voltadas ao manejo adequado do solo, da água e da biodiversidade na transição agroecológica;

- A uma análise dos princípios sustentáveis do manejo integrado de pragas;

- Ao estudo do controle biológico como uma alternativa promissora para o manejo de pragas em sistemas agrícolas sustentáveis, visto que se constitui em um processo de regulação biológica da densidade populacional de pragas, através do uso de inimigos naturais ou agentes de controle biológico;

- Ao conhecimento dos defensivos naturais, que são produtos de origem natural, que possuem baixa toxicidade ao homem e ao ambiente, mas que apresentam potencial de uso no controle de insetos e microrganismos nocivos às lavouras.

Ao final dessas aulas foi promovido um debate em equipe, onde cada equipe solucionou questões relacionadas o uso do MIP em processos agroecológicos. Em seguida, todas as respostas foram expostas e debatidas entre as equipes.

As aulas 7 e 8 foram dedicadas à discussão sobre práticas que promovem a melhoria da qualidade do solo, o aumento da biodiversidade e a melhoria da qualidade da água. Assim, nas aulas 7 e 8 da segunda sequência didática foram abordados:

- Conceitos e Bases Agroecológicas;

- A permacultura, a agricultura natural, a agricultura biodinâmica, a agricultura orgânica, a agrossilvicultura; com destaque para os Sistemas Agroflorestais, como alternativa para o desenvolvimento rural sustentável, e transformação das atividades de produção degradantes em regenerativas.

Ao final dessas aulas, foi aplicada a quarta coleta de dados, realizada através da análise e resposta, em grupo, a questões sobre as características inerentes a diferentes tipos de agricultura de base ecológica. As respostas serviram à montagem coletiva de um quadro exposto na lousa e foram analisadas quanto à sua coerência ao entendimento dos conceitos e das bases agroecológicas e à capacidade de reflexão sobre processos de produção agrícola sustentável.

\section{Critérios de análise dos resultados}

Os textos dissertativo-argumentativos produzidos pelos estudantes foram analisados de acordo com os critérios de avaliação descritos no quadro 1.

Quadro 1 - Critérios de avaliação dos textos dissertativos elaborados pelos estudantes

\begin{tabular}{|l|l|l|l|}
\hline Item & \multicolumn{1}{|c|}{ Critério de avaliação } & \multicolumn{1}{|c|}{ Foco da análise } & \multicolumn{1}{|c|}{$\begin{array}{c}\text { Pontuação } \\
\text { atribuída }\end{array}$} \\
\hline 1 & Exposição e Tese & $\begin{array}{l}\text { Análise da capacidade de contextualização da ideia central } \\
\text { do texto, da indicação do ponto que pretendeu defender e } \\
\text { a exposição da tese. }\end{array}$ & Até 1 ponto \\
\hline 2 & Estratégias de Argumentação & $\begin{array}{l}\text { Análise do argumento utilizado para convencer o leitor a } \\
\text { concordar com a tese defendida }\end{array}$ & Até 1 ponto \\
\hline 3 & Coerência e Coesão & $\begin{array}{l}\text { Análise da organização das ideias e convergência dos argu- } \\
\text { mentos apresentados ao longo do texto }\end{array}$ & Até 1 ponto \\
\hline 4 & $\begin{array}{l}\text { Conclusão e proposta de In- } \\
\text { tervenção }\end{array}$ & $\begin{array}{l}\text { Análise da solução proposta pelo estudante para o problema } \\
\text { apresentado }\end{array}$ & Até 1 ponto \\
\hline
\end{tabular}

Fonte: adaptado de Delprete (2012). 
Com base nos critérios descritos acima, a atividade de produção de texto correspondeu a 4 pontos, sendo que cada texto foi pontuado por meio do somatório do valor obtido para cada um desses critérios. A partir da tabulação da pontuação obtida pelos alunos das três turmas foi gerada uma média, que foi convertida em um percentual, variando de 0 a $100 \%$, representativo do potencial individual de reflexão e exposição dos conhecimentos adquiridos sobre os conteúdos relacionados ao pacote tecnológico do agronegócio e o seu papel na solução da fome.

Na segunda atividade, as respostas às questões reflexivas foram avaliadas em relação à (1) cooperação e apoio mútuo dos integrantes das equipes para solucionar as questões propostas e (2) à capacidade de análise e compreensão dos 'mitos relacionados à ciência', (3) à habilidade das equipes em avaliar a razoabilidade, confiabilidade e validade dos 'mitos' apresentados no estudo de caso da Chapada do Apodi e, (4) a habilidade das equipes em correlacionar 'os mitos apresentados no estudo de caso' aos 'mitos relacionados à ciência', aplicando e defendendo argumentos e gerando novas opiniões sobre o debate proposto. Com base nesses critérios, para cada equipe, foi atribuído até 1 ponto às respostas formuladas para a primeira e segunda etapas da atividade, totalizando 2 pontos. Foi gerada uma média das notas obtidas pelas equipes das três turmas, que foi convertida em um percentual de êxito das respostas, de 0 a 100\%.

$\mathrm{Na}$ terceira atividade, as respostas às questões debatidas foram avaliadas em relação à (1) cooperação e apoio mútuo dos integrantes das equipes para solucionar as questões propostas (2) à compreensão dos conceitos de Agroecologia, sustentabilidade, transição agroecológica, (3) capacidade de entendimento dos processos agroecológicos de controle de pragas agrícolas, e (4) à capacidade de identificação dos principais tipos de controle, bem como seus procedimentos. Com base nesses critérios, para cada equipe, foram atribuídos três níveis de desempenho: insuficiente (quando a resposta não respondeu à pergunta), regular (quando a resposta respondeu parcialmente a pergunta) e suficiente (quando a resposta respondeu à pergunta). Foi gerada uma média dos resultados obtidos pelas três turmas, em relação a esses três níveis de avaliação de aprendizagem.

$\mathrm{Na}$ quarta atividade, os critérios de análise das respostas para serem consideradas (suficientes) corresponderam à compreensão: (1) da ciclagem de nutrientes através da cobertura do solo, com a função de fertilizar o solo e protegê-lo; (2) dos consórcios de culturas, que possibilitam o estabelecimento de espécies com requerimentos mais exigentes; (3) da fertilização orgânica (compostagem, adubo verde, biofertilizantes, etc.); (4) do controle biológico de pragas; (5) da poda, como manejo essencial ao êxito dos sistemas agroflorestais.

\section{Resultados e Discussão}

De acordo com a análise dos textos dissertativo-argumentativos, a pontuação percentual média alcançada pelos estudantes correspondeu a 53,6\%, com base nos critérios estabelecidos. Apesar de abaixo da média de $60 \%$ (equivalente à média de 6 pontos), esse resultado evidencia a aquisição de habilidades cognitivas por parte dos alunos, levandose em consideração que os debates em sala de aula envolveram informações até então desconhecidas pelos estudantes, uma vez que, quando questionados sobre o tema, no início da aula, a maioria declarou desconhecê-lo. 
Esse resultado também reflete a dificuldade dos estudantes em elaborar um texto dissertativo-argumentativo, devido às limitações de base relacionadas à escrita, bem como à inobservância dos critérios apresentados no barema que acompanhou as instruções da atividade. Como discute Vigotski (2001), a motivação para o ato de escrever se encontra distante das necessidades imediatas do aprendiz, além da linguagem escrita ter uma dificuldade inerente, por ser mais abstrata, exigindo um trabalho mais consciente de estruturação do significado. Como mostra a transcrição $(T)$ abaixo, referente à introdução de um texto que obteve resultado abaixo da média:

(T) Aluno: A fome é um grande problema no mundo, aonde vem trazendo muitos transtornos alguns dele são a luta para a busca do alimento e a falência do indivíduo por não encontrá-lo. O agronegócio é o principal vetor para terminar com fome no mundo, temos, por exemplo, a agricultura familiar que no Brasil a população é alimentada por ela. Se apenas um pequeno produtor junto a outros são capazes de alimentar uma população brasileira, por que não o mundo com inúmeros produtores?

Essa parte introdutória do texto demonstra que o estudante não compreendeu diferenças básicas entre agronegócio e agricultura familiar, e em consequência disso, evidencia dificuldade em apresentar uma argumentação coerente.

Por outro lado, pelo fato do plano de aula contextualizar o assunto abordado e demostrar, na prática, como os processos estão inseridos no nosso cotidiano, foi constatado que, quando os conceitos são apresentados através de discussões contextualizadas, estes se mostraram mais inteligíveis e motivadores para a aprendizagem, bem como desafiam a imaginação e a compreensão dos estudantes (KRASILCHIK, 2004). Como mostra a transcrição (T) referente a um texto que apresentou aproveitamento acima da média: "A Revolução verde ocorreu no final de 1940, com o objetivo de aumentar a produção e dessa forma acabar com a fome no mundo" ( $T$ - Aluno). Apesar da proposta ter sido feita, esse objetivo não foi devidamente alcançado, pois milhares de pessoas ainda sofrem por conta da falta de alimentação. O que era para ser, o fim da insegurança alimentar e penosidade do trabalho manual no campo, tornou-se apenas práticas agrícolas, com grandes usos de máquinas, fertilizantes e agrotóxicos. A Revolução verde, trouxe na realidade a concentração de terras, dependências dos proprietários rurais por insumos, produzidos por multinacionais". Esse trecho demostra a capacidade de contextualização e argumentação do estudante na defesa do seu ponto de vista, tendo como base a ideia central fornecida.

Na segunda coleta de dados foi constatado um aproveitamento de $68 \%$ das respostas às atividades reflexivas em grupo, quando os alunos, em equipe, relacionaram as questões da neutralidade da ciência, com o setor do agronegócio ( $1^{\text {a }}$ etapa); e também realizaram uma análise coletiva dos mitos apresentados no estudo de caso da Chapada do Apodi, como tendo sido propagados pelo agronegócio ( $2^{\mathrm{a}}$ etapa). Esse percentual, que foi superior ao da primeira atividade, pode ter sido alcançado em função de uma maior familiaridade com a temática, que já havia sido discutida na aula anterior e também devido ao fato dessa atividade ter sido realizada em equipe, o que permite a cooperação mútua e, consequentemente, maior robustez da argumentação. Essa atividade se caracterizou como uma ação educativa que considerou a natureza social e socializadora do ensino, permitindo trocas entre o caráter social do conhecimento e a prática educativa (COLL, 2009), e também promoveu a exposição de diferentes pontos de vista, interpretações de fatos científicos, além de discussões e 
reflexões coletivas para o desenvolvimento do senso crítico e o exercício da cidadania, com base em opiniões informadas (PAIXÃO, 2018).

Conforme preconizado por Moreira (2012), o material fornecido aos estudantes deve ser relacionável à sua estrutura cognitiva, e o aprendiz deve ter o conhecimento prévio necessário para fazer essa relação de forma não arbitrária e não literal. Logo, a conexão entre conhecimentos prévios dos estudantes e a sua ressignificação, através da reflexão resultante do aproveitamento do material impresso fornecido, está representada na seguinte transcrição $(\mathrm{T})$ da resposta de uma equipe, à atividade Desmitificando a neutralidade da ciência, que demonstra o entendimento de que a ciência e seus produtos nem sempre são neutros, uma vez que em muitas situações são desenvolvidos no atendimento de interesses de corporações e governos:

(T) Equipe: Determinados produtos tecnológicos estão sendo alvo de controvérsias, debates e interesses. O agronegócio utiliza a mídia para debater esses mitos para que a sociedade acredite sobre essas reflexões e se engane. Na verdade, as grandes empresas de agronegócio não se importam com as pessoas e nem com meio ambiente, querendo apenas o lucro. Além disso, o governo debate que existe uma só forma de combater a fome no Brasil, com a utilização de agrotóxicos, e que pode ser aplicado por qualquer pessoa e etc.

Assim como discutido por Andrade e Carvalho (2002), Pinheiro et al., (2007), Quse e De Longh (2005) e Santos (2007), a abordagem das relações envolvendo Ciência, Tecnologia, Sociedade e Ambiente (CTSA) na sequência didática, possibilitou a contextualização do estudo da Revolução Verde e da Transição Agroecológica, promovendo a motivação dos alunos e facilitando a aprendizagem, bem como ampliando a capacidade de se expressarem criticamente diante de situações do cotidiano.

Os resultados do processo de compreensão pelos estudantes, dos princípios e bases agroecológicas e do manejo de pragas agrícolas, analisados na terceira coleta de dados, indicaram um percentual de adequação das respostas das equipes de apenas 20\%, considerado insuficiente, pois apesar das respostas estarem dentro do contexto, estas não corresponderam ao que foi solicitado no enunciado da questão, como mostra a transcrição (T) da resposta (considerada insuficiente) da equipe para a questão 'Quais são as principais etapas para o desenvolvimento e implantação do Manejo Integrado de Pragas MIP?':

(T) da resposta (considerada insuficiente) - A implantação do manejo, ao contrário é mais exigente em conhecimento e suas interações, esse conhecimento nem sempre está disponível e muitas vezes tem um nível de complexibilidade elevado demais para ser assimilado pelo produtor. O manejo requer um monitoramento constante da população de insetos nocivos e de seus inimigos naturais, com inúmeras tomadas de decisão por parte do produtor durante todo ciclo da cultura.

Outros $20 \%$ das respostas das equipes foram classificados como regulares porque ainda que estivessem corretas, eram incompletas, como mostra a transcrição ( $T$ ) da resposta (considerada regular) da equipe para a questão: 'Quais são as principais etapas para o desenvolvimento e implantação do MIP?'

( $\mathrm{T}$ ) da resposta (considerada regular) - "Identificar as pragas, saber o ciclo de vida delas, ver o melhor manejo para ser implantado (identificar predadores naturais), combinando 
melhor produção." Nesta resposta faltou mencionar o monitoramento do nível de dano causado pela 'praga', etapa imprescindível para tomada de decisão por parte do produtor.

E $60 \%$ das respostas foram consideradas suficientes, por apresentarem uma compreensão do assunto e por estarem completas, como pode ser visto na transcrição $(T)$ de duas respostas (consideradas suficientes) das equipes para as seguintes questões: 'Quais são as principais etapas para o desenvolvimento e implantação do MIP?', ‘De quais maneiras o MIP pode contribuir com a produção agrícola sustentável?'

(T) da resposta (considerada suficiente) - "Identificar e conhecer a praga, fazer o monitoramento para saber se vai tomar uma medida ou não, e logo após, realizar o controle da praga".

(T) da resposta (considerada suficiente) - O MIP pode contribuir controlando as pragas de forma sustentável e economicamente viável aos produtores, sem prejudicar a sua qualidade de vida, diminuindo também os danos ambientais, através de estudos para determinar o ciclo das pragas e buscar manter as pragas em níveis toleráveis.

Nesse sentido, segundo Schroeder, Ferrari e Sylvia (2009), ao se engajar nas interações discursivas com o professor nas situações de aprendizagem em sala de aula, o aluno estabelece uma melhor conexão entre a compreensão do cotidiano e o conhecimento científico a respeito da temática abordada. Essa característica ficou evidente quando os alunos fizeram questionamentos, tais como: "É possível controlar/combater as pragas que acometem uma monocultura, só com o uso do controle biológico?"; "Quando se usa transgênicos ou insumos químicos no MIP, a produção deixa de ser considerada de base Agroecológica?". O que também pode ter contribuído para um melhor desempenho dos alunos nessa atividade é o fato dos planos de aula que compuseram essa sequência, possuírem ideias-âncora relevantes com as quais as respostas podem ser relacionadas (MOREIRA, 2012).

$\mathrm{Na}$ quarta atividade, após os alunos apontarem as características dos modelos de produção agroecológica, os mesmos foram estimulados a responder como esses processos ocorrem. Para a questão: 'Quais são as características dos diferentes tipos das linhas de produção agroecológica que contribuíram para a construção dos sistemas agroflorestais sucessionais', um aluno respondeu: "ciclagem de nutrientes". Logo o professor o interrogou: "e como ocorre essa ciclagem?". E ele rebateu: "cobertura orgânica do solo...". Nesse sentido, entende-se que a abordagem comunicativa fornece "[...] a perspectiva sobre como o professor trabalha as intenções e o conteúdo do ensino por meio das diferentes intervenções pedagógicas, que resultam em diferentes padrões de interação" (MORTIMER; SCOTT, 2002, p. 287).

Ao estimular interações discursivas com o mediador, são estabelecidas conexões entre os conhecimentos prévios dos estudantes com o conhecimento científico em geral. Assim, proporciona-se a construção de um processo coletivo e cooperativo de aprendizagem, embasado na teoria sociointeracionista de Vigotski (2001), que privilegia atividades de interação e discussão em grupos de alunos, mediadas pelo professor. Segundo Freire (2003), "[...] ao ser produzido o conhecimento novo, este supera o outro que antes foi novo e se fez velho e 'se dispõe' a ser ultrapassado por outro amanhã". Por isso é tão fundamental trazer à tona os conhecimentos prévios e promover condições à produção do conhecimento ainda não existente. 


\section{Avaliação do projeto de intervenção}

A pesquisa demonstrou que a aplicação de sequências didáticas sobre Agroecologia nas turmas do Curso Técnico em Agropecuária resultou em uma validação interna das duas SD, através da constatação da aquisição de competências e habilidades dos estudantes na resolução de problemas sobre o assunto em questão, o que foi interpretado como ganhos de aprendizagem. Competências e habilidades foram observadas/verificadas através de respostas escritas e orais às atividades, revelando uma progressão no domínio dos conteúdos, com o avançar das aulas e das informações expostas.

A estimulação dos alunos nas discussões, através dos debates, fazendo com que atuassem como sujeitos ativos do processo de aprendizagem individual e coletivo, propiciou o uso das ideias-âncora, fornecidas através dos planos de aula, na compreensão do conteúdo, a partir de suas próprias experiências, bem como viabilizou um posicionamento crítico em relação a questões sociocientíficas relevantes para sua formação como cidadãos. Assim, as atividades de interação e discussão entre os alunos proporcionaram a construção de um processo coletivo e cooperativo de aprendizagem. Isso mobilizou os estudantes no que diz respeito à motivação, ao interesse e à participação nas atividades propostas.

\section{Considerações Finais}

O primeiro ciclo de aplicação das sequências didáticas permitiu o levantamento de algumas considerações que devem ser feitas no sentido de aprimorá-las, visando uma nova iteração dos estudos para seu teste e desenvolvimento. Após as intervenções, foi observado que, para alguns estudantes, algumas concepções sobre a real contribuição da 'Revolução Verde' no combate à fome permaneceram inalteradas, mas estas não foram embasadas por informações da literatura especializada ou por dados de órgãos oficiais. Esses resultados indicam que será preciso dedicar mais esforço à orientação dos alunos quanto ao levantamento de informações para embasar as suas argumentações, assim como à discussão das concepções emergentes em sala de aula.

Esse primeiro ciclo de aplicação das sequências didáticas permitiu a identificação da necessidade de se trabalhar mais a linguagem escrita durante as atividades requeridas nos planos de aula, em função da dificuldade dos estudantes em responder questões abertas, e também à demanda pelo uso de estratégias de ensino diversificadas, como por exemplo, o desenvolvimento e uso combinado de jogos, desenhos, poesias e músicas, dentre outros recursos.

Além de beneficiar o público-alvo desta pesquisa, os estudantes do curso técnico em agropecuária, a metodologia adotada permitiu a formação continuada de professor e pesquisador educacional envolvidos nesta pesquisa, através de um processo colaborativo que proporcionou, simultaneamente, o progresso da pesquisa em ensino de Agroecologia e o próprio ensino.

As sequências didáticas foram utilizadas para melhorar a prática educativa em um contexto educacional específico, configurando-se como uma solução localmente apropriada que tem potencial para ser reproduzida em outros contextos educacionais.

Diante dos resultados deste primeiro protótipo das sequências didáticas, espera-se que os princípios de planejamento usados em sua construção possam ser empregados por 
profissionais da educação em outros contextos de ensino e para a produção de material didático facilmente adaptável, socialmente relevante e de baixo custo.

\section{Referências}

ANDRADE, E. C.; CARVALHO, L. M. O pro-álcool e algumas relações CTS concebidas por alunos de $6^{a}$ série do ensino fundamental. Ciência \& Educação, Bauru, v. 8, n. 2, p. 167-185, 2002. DOI: http://doi. org/d9t748

AGUIAR, M. V. Educação em agroecologia: que formação para a sustentabilidade? Agriculturas, Rio de Janeiro, v. 7, n. 4, p. 4-6, 2010. Disponível em: https://tinyurl.com/y9ca4ut2. Acesso em: 1 jun. 2020.

ARAÚJO, J. L.; FAQUIN, V.; VIEIRA, N. M. B.; OLIVEIRA, M. V. C.; SOARES, A. A.; RODRIGUES, C. R.; MESQUITA, A. C. Crescimento e produção do arroz sob diferentes proporções de nitrato e amônio. Revista Brasileira de Ciência do Solo, Viçosa, v. 36, n. 3, p. 921-930, 2012. DOI: http://doi.org/dx92

BRASIL. Decreto no 7.794, de 20 de agosto de 2012. Institui a política nacional de agroecologia e produção orgânica. Diário Oficial da União: Seção 1, Brasília, p. 4, 21 ago. 2012.

BRASIL. Ministério da Educação. Lei no 9.394, de 20 de dezembro de 1996. Estabelece as diretrizes e bases da educação nacional. Brasília: Presidência da República, 1996. Disponível em: http://www. planalto.gov.br/ccivil_03/leis/l9394.htm. Acesso em: 2 jul. 2018.

BEATRICI, R. F.; MELLO, U. P. (org.). Curso técnico em agropecuária ecológica com ênfase em biocombustíveis: fortalecer a resistência camponesa. Ronda Alta: FUNDEP, 2007.

COLL, C. O construtivismo na sala de aula. São Paulo: Ática, 2009.

CONGRESO IBERO AMERICANO DE PSICOLOGÍA DE LAS ORGANIZACIONES Y EL TRABAJO, 3., 2013, Rosario. Actas [...]. Rosário: Universidad Nacional de Rosario, 2013.

DELPRETE, B. Saiba o que é o texto dissertativo-argumentativo cobrado na redação do ENEM. [S.I.]: Universia Brasil, 2012. Disponível em: https://tinyurl.com/ydx4c4eh. Acesso em: 3 jul. 2018.

FREIRE, P. Cartas a Cristina: reflexões sobre minha vida e minha práxis. 2. ed. São Paulo: UNESP, 2003.

KRASILCHIK, M. Prática de ensino de biologia. 4. ed. São Paulo: Edusp, 2004.

MÉHEUT, M. Teaching-learning sequences tools for learning and/or research. In: BOERSMA, K. et al. (ed.). Research and the quality of science education. Dordrecht: Springer, 2005. p. 195-207.

MOREIRA, M. A. ¿Al afinal, qué es aprendizaje significativo? Qurriculum: revista de teoría, investigación y práctica educativa, La Laguna, n. 25, p. 29-56, 2012. Disponível em: https://dialnet. unirioja.es/servlet/articulo?codigo=3943478. Acesso em: 2 jun. 2018.

MORTIMER, E. F.; SCOTT, P. Atividade discursiva nas salas de aula de ciências: uma ferramenta sociocultural para analisar e planejar o ensino. Investigações em Ensino de Ciências, Porto Alegre, v. 7, n. 3, p. 283-306, 2002. Disponível em: https://tinyurl.com/ya2z6xxs. Acesso em: 2 jun. 2018.

PAIXÃO, J. F. A educação científica e o movimento ciência, tecnologia, sociedade e ambiente (CTSA). In: PAIXÃO, J. F. (org.). Educação, meio ambiente e comunidade: experiências do IF Baiano. Salvador: EDUFBA, 2018. p. 11-22. 
PINHEIRO, N. A. M.; SILVEIRA R. M. C. F.; BAZZO, W. A. Ciência, tecnologia e sociedade: a relevância do enfoque CTS para o contexto do ensino médio. Ciência \& Educação, Bauru, v. 13, n. 1, p. 71-84, 2007. DOI: http://doi.org/br3c9f

PLOMP, T.; NIEVEEN, N. Educational design research: an introduction. In: PLOMP, T.; NIEVEEN, N. (ed.). An introduction to educational design research. Enschede: Netherlands Institute for Curriculum Development, 2009. p. 9-35.

QUSE, L.; DE LONGH, A. L. ¿Qué dicen los docentes de biología del nivel medio sobre la educación CTS?: diagnóstico en Córdoba, Argentina. Revista Electrónica de Enseñanza de las Ciencias, Vigo, v. 4, n. 2, p. 1-14, 2005.

RIGOTTO, R. M. et al. O verde da economia no campo: desafios à pesquisa e às políticas públicas para a promoção da saúde no avanço da modernização agrícola. Ciência \& Saúde Coletiva, Rio de Janeiro, v. 17, n. 6, p. 1533-1542, 2012. DOI: http://doi.org/dx93

SANTOS, W. L. Contextualização no ensino de ciências por meio de temas CTS em uma perspectiva crítica. Ciência \& Ensino, Campinas, v. 1, n. esp., p. 1-12, 2007.

SCHROEDER, E.; FERRARI, N.; SYLVIA, M. A construção dos conceitos científicos em aulas de ciências: contribuições da teoria histórico-cultural do desenvolvimento. In: ENCONTRO NACIONAL DE PESQUISA EM EDUCAÇÃO EM CIÊNCIAS, 7., 2009, Florianópolis. Anais [...] Florianópolis: ABRAPEC, 2009.

VIGOTSKI, L. S. A construção do pensamento e da linguagem. São Paulo: Martins Fontes, 2001.

ZABALA, A. A. Prática educativa: como ensinar. Porto Alegre: Artmed, 1998. 